\title{
The Signature: A Never-Sent Letter to the Editors of Neurology, Updated With Commentary and Guidelines for the Future
}

\section{Benjamin M Blumberg}

Department of Neurology, Microbiology and Immunology, University of Rochester Medical School, NY, USA

*Corresponding author: Benjamin M Blumberg, Former Associate Professor, Department of Neurology, Microbiology and Immunology, University of Rochester Medical School, 6 Horizon Rd, Apt 2302, Fort Lee, NY, 07024, USA, Tel: +1 585-275-2100; E-mail: bbrl@aol.com

Rec date: Oct 26, 2016; Acc date: Oct 30, 2016; Pub date: Oct 31, 2016

Copyright: (c) 2016 Blumberg BM. This is an open-access article distributed under the terms of the Creative Commons Attribution License, which permits unrestricted use, distribution, and reproduction in any medium, provided the original author and source are credited.

\section{Letter to Editor}

\section{The Original Letter, Not Sent in 2009}

Sirs,

A recent paper in Neurology by Annette Schrag et al. [1,2] with an accompanying editorial by D.L. Gilbert and R. Kurlan [2] caught my attention as being a perfect example of what modern medicine is doing, right and wrong in its current policies regarding the statistical treatment of patient data. Schrag et al. did a magnificent job surveying a database of 678,862 UK patients to search for associations between streptococcal infection and certain neuropsychiatric disorders including tics, Tourette syndrome and obsessive-compulsive disorder collectively termed PANDAS (Pediatric Autoimmune Neuropsychiatric Disorders Associated with Streptococcus B infection; Swedo et al. [3]). Schrag et al. [1] used conditional logistic regression to identify controls matched for age and sex and wound up with 254 cases and 2,211 controls. They sliced and diced this data for such other variables as antibiotic treatment and ethnicity, but in the end could not confirm a statistically significant association between streptococcal infection and the PANDAS [1].

So are we to believe that there really is no association, or is there something wrong with the statistics? Clearly the authors still think there is an association, because in comparing their results against an older USA study [4] which found twice as high an association, they were unable to point out specific reasons for the different findings [1]. They went on to say that only a prohibitively expensive prospective study with high diagnostic accuracy and laboratory confirmation of streptococcal infection could overcome this problem [1] - but then cited a more recent, prospective US study of exactly this type [5] in which the degree of association was also found to be vanishingly low.

Similarly, there is much anecdotal evidence that administration of the MMR vaccine to infants and children below 3 years of age is often followed closely by reversal and loss of developmental landmarks and abilities related to socialization, i.e. by the development of autistic syndrome disorder (ASD). Remarkably, we are currently in the midst of an autism epidemic, in which one in fewer than 100 children presents with ASD following exposure to a vaccine or environmental agent, yet studies using population-based statistics show no difference in ASD incidence between children who received the MMR and those who did not [6].

I think that there is indeed something wrong with the use of population-based statistics in these two cases. The original suspicions of an association between streptococcal infection and the PANDAS were based on a close temporal relationship between the onset of infection and the development of the disorder, and were supported by the clear correlation between neuropathologically identified infection of the basal ganglia and its neuronal projections to target areas [7]. The situation is analogous to the well-known association of immunoreactivity to streptococcal infection in the case of rheumatic heart disease [8]. Similarly, the close temporal relationship between infection with measles virus (part of the MMR) and ASD is ignored, despite the well-known role of measles virus in causing neurological diseases such as sub-acute sclerosing panencephalities (SSPE) [9].

I assert that when population-based statistics are used in an effort to demonstrate an association between a disorder and a suspect agent, and the signal goes away, this is in fact the signature of either a multiagent infection, or an infection with an agent that can take on multiple forms and functions, or a ubiquitous commensal agent, and that population-based statistics are simply not appropriate for analysis of such disorders, because the temporal data are ignored and thrown away. Unfortunately, the appropriate mathematics for recognizing and analyzing multiagent diseases are currently lacking, but could be constructed using algorithms that give due weight to the temporal relationships.

We are living in a post-Koch's postulates age, where important diseases of unknown etiology are becoming rare. The agents of a few new diseases, such as Lyme disease, MERS and SARS, have been identified by classical methods, but probably the majority of wellknown diseases of unsolved etiology nowadays are caused by multiple viruses and ubiquitous commensal form- and function-shifting bacteria. The problem of population-based statistics is that in certain cases where the temporal relationship is strong but the neuropathological correlate is lacking, our inability to identify the agent tends to close off investigation and debate. Perhaps a fresh look at etiology in Autism Syndrome Disorders, the PANDAS and ALS (Lou Gehrig's disease) will serve as models for relieving this statistical impasse.

\section{Commentary on the Letter, Updated for 2016}

A search of PubMed for PANDAS (10/27/2016) reveals that the current status of the association of Streptococcus B agents with tics, Tourette's syndrome and OCD is still uncertain. The symptoms of PANDAS-type disorders are now being treated by procedures as disparate as antibiotic prophylaxis, tonsillectomy, plasmapheresis, and especially manipulation of the patient's immune status with IVIG [10-14]. Each of these measures has had some limited success, but none can reliably treat a random patient, and none has really addressed the cause of the disorders: the suspected Streptococcus pyogenes bacteria [10-14].

Our understanding of the capabilities of these bacteria is still expanding, and we now consider ourselves in the post-antibiotic age, 
where bacterial resistance to the antibiotics that did so much to make the practice of medicine seem like magic in the years from the 1930's through the 1990's is now becoming common. Streptococcus pyogenes spp. have the ability to resist antibiotics in at least five ways: by generating enzymes that inactivate the antibiotics; by modifying their cell walls so as to exclude the antibiotics from entering the bacteria; by adopting metabolically inert forms that resist the action of the antibiotics; by hiding out inside infected cells in persistent forms that do minimal damage to the cells; and also by co-operatively generating a biofilm and hiding under it, thereby avoiding contact with the antibiotic $[7,15]$. Faced with such a formidable and devious bacterial armamentum, it is no surprise that the PANDAS and their statistics are still in flux.

The situation regarding the relationship between administration of the MMR vaccine and acquisition of autism in vaccinated children is quite different. Here, it turns out that there is a close relationship after all, but it has been concealed from the public by the CDC in the interests of VICAP, the government program meant to reimburse the families of infants injured by vaccines, and thus protect the vaccine manufacturers. The CDC concealed the connection by fiddling their numbers, so no matter how sophisticated the mathematical treatment of the data, as required by Neurology's new standards, the results would still be cooked. This government malfeasance was recently revealed by a whistleblower at CDC, Dr. William Thompson. The story has been all over the Internet for a while, and recently it has been published in the Townsend Letter $[16,17]$.

Remarkably, this fiddling of data combined with the assertion that studies using population-based statistics show no difference in ASD incidence between children who received the MMR and those who did not has buffaloed some of the brightest minds in America. In a brief conversation with Dr. Thomas R. Insel, head of the NINDS, at a NYAS meeting in 2014, I asked him why nobody had found a connection between the MMR and autism, and he responded reflexively with the "no difference in ASD incidence" argument.

\section{Guidelines for the future - Magic overcomes outrage!}

So where do we go from here in regard to the statistical conundrums of the PANDAS and the MMR/autism controversy? Neurology was under the chief editorship of Dr. Robert Griggs when the new standards for mathematical rigor were insitituted. Now it is under the chief editorship of Dr. Robert Gross, who recently presented an article on medieval medicine in Saudi Arabia that showed, on the cover of the Sept. 6 volume, pins inserted through the suture lines of a skull to relieve epilepsy symptoms in a patient. I took Dr. Gross to task for this article [18], which wondered "whether the demon was successfully expelled", as not being appropriate as a model for modern neurological practice, but perhaps I was wrong. It now occurs to me that the best ways out of the conundrum and controversy above, may indeed be by expelling the demons, i.e., by magic. Even Dr. Paul Offitt, in his book "Autism's False Prophets"6, refers to magic in medicine in a quote from Thomas Szasz:

"When religion was strong and science weak, men mistook magic for medicine. Now, when science is strong and religion weak, men mistake medicine for magic."

The magic I would commend to your attention for treatment of the PANDAS is the Marshall Protocol $[19,20]$. This protocol was used by Dr. Trevor Marshall to cure his own case of sarcoidosis, and he thinks it applies to all Th1-type bacterial infections. The Marshall Protocol has been available on the Internet for several years, but has not gained nearly as much traction as it deserves. The reason, I think, is that the underlying disorder is one of those exponential problems that crop up occasionally in biology, and is difficult for the unprepared mind to visualize.

To help visualize it, think of the old problem of the Indian Prince who loves the Princess but is required to place $2 \mathrm{x}$ grains of sand on the 64 squares of a chessboard, where $x=0$ ( 1 grain) for the first square, $\mathrm{x}=1$ ( 2 grains) for the second, $\mathrm{x}=2$ ( 4 grains) for the third... etc., to win her hand. Around the 35th square, not all the dump trucks in the world can carry the required amount of sand. A different way to look at this is the old lily pad on a pond problem - here the element of time enters. If a lily pad growing on a pond doubles in size every day, on which day will the pad occupy half the area of the pond? The obvious answer is: on the next-to-last day - but when the last day may come is the serious part of the question.

The protocol itself [19] can be described as alternating doses of an antibiotic, usually a broad-spectrum antibiotic at first, followed by the drug benicar (Olmesartan). Each round of treatment thus consists of antibiotic/benicar, and can be visualized as one turn of a crank. The antibiotic kills some of the bacteria, but not all, and the survivors then adopt one or more of the various means of resistance noted above, and are held in this resistant state by the innate immune system. The drug benicar is an antagonist of the Vitamin $\mathrm{D}$ receptor which controls the innate immune system, so treatment with benicar releases the bacteria to grow again and thus again become susceptible to the antibiotic. The problem here is that each turn of the crank takes about two weeks: one week for the antibiotic to work, and a second week for the benicar to take effect. If only a small fraction of the bacteria are killed with every turn of the crank, it may take many turns of the crank - say, 50 turns = 2 years - before the infection even begins to be controlled. There are probably few physicians who would be willing to continue this protocol for 2 years before any results are noted, which is why it is not yet widely accepted. But that is the magic - you have to keep the faith, baby.

In practice, the protocol is somewhat different, of course. Treatment actually consists of a constant dosage of benicar, punctuated by doses of antibiotics. The antibiotics can be varied and optimized during the course of treatment, to reflect laboratory findings on the bacterial strains involved. But the charm of the Marshall Protocol is that it will work in most cases without exact advance knowledge of the causative agent. The benicar treatment makes life under treatment difficult, because all sources of Vitamin D must be restricted, including sunlight. This is somewhat balanced by the possibility that the Marshall Protocol may work on other difficult-to-treat disorders besides the PANDAS, such as ALS and Lyme disease.

Finally, what magic can be used to fight a reluctant Federal Government and rationalize the administration of vaccines so that the present (wholly unacceptable) incidence of $1 / 68$ children who acquire ASD can be brought back to its level of $4 / 10,000$ as of 20 years ago? Here, the magic is just two words: "Reporting Period". Currently, the reporting periods for autism, as noted in the whistleblower's report are $16,17,18$ and 36 months. That is, data is collected every 1 or 3 years on which children received the MMR and other vaccines, and which children did or did not develop an ASD of some sort. Under the current guidelines of the American Pediatric Association, at least 12 vaccines are given, some in repeated doses, to infants and toddlers between the ages of 1 and 3. This means that every two to three months, a dose of vaccine is given, often enforced by school 
restrictions for the children of those parents who object to this heavy vaccination schedule. In my opinion, it is the mismatch between the short vaccine intervals (at least one dose every 2-3 months) and the current lengthy reporting periods (1-3 years) that causes the statistical error that ignores the temporal relationship between vaccination and onset of autistic disorder. If the Reporting Period were made shorter, every 2-3 months, consistent with the vaccination schedule, the association between vaccination and disease onset would stand out a mile, and then the debate about whether and which vaccinations cause autism could proceed on a rational basis.

By far the best books on the MMR/autism problem were written by Dr. Paul Offitt, the inventor of the rotavirus vaccine among other accomplishments. When Dr. Offitt's first book "Autism's False Prophets" was first published, I sent him a letter telling him that he was wrong about there being no connection between the MMR and onset of ASD. This was perhaps not the best way of introducing myself, and I did not hear back from him, but now I know what I did not know in 2008: the magic words "Reporting Period", which form a sort of bridge between a bench scientist like myself, the pediatrician (and vaccine developer) Dr. Offitt, and the epidemiologists and statisticians like Dr. Walter Zaharodny who derived the outrageous but probably correct figure of ASDs now being acquired by one in 68 children [21]. Perhaps if I had told Dr. Offitt that he had ignored the importance of the mismatch between the reporting period and the pediatric vaccination schedule, he would have understood. Hopefully, you, the reader, will now understand.

"Autism's false prophets" was all about the ways in which a federal government bureaucrat influenced a shift to early and frequent administration of numerous vaccines to infants in an effort to promote health from cradle to grave [22], and about how a report by Dr. Andrew Wakefield that linked the MMR with autism through gut toxicity became grossly distorted and led to a general distaste for vaccines in the mind of the public. I myself was asked (unofficially) by $\mathrm{NIH}$ personnel to investigate the presence of measles virus in Peyer's Patch samples in gut from autistic and control patients, but I never liked the story and did not do the work, and so have remained on the sidelines of this unfolding tragedy for nearly 20 years.

Dr. Offitt then wrote a second book, "Deadly Choices: how the antivaccine movement threatens us all" [23] to deal with this problem. Here, Dr. Offitt points out that the risks of not giving the vaccines for their intended purposes is worse for the individual than taking them and subjecting the infant to the possibility of autism, and infinitely worse for the general public due to the possibility that a sufficient number of unvaccinated children can easily start an epidemic of e.g. measles, as happened in England when groups of parents rebelled against the MMR [23]. In the remainder of this concluding paragraph, I will detail my views on the subject of vaccination. Not everyone will agree with them.

1. One must never forget that ours is a world of risk, and each of us is a survivor. Measles is still the number two cause of morbidity and mortality among children in Africa, second only to malaria, and can easily again becomes a blight in the West if vaccinations are ignored. Pertussis would also be unwelcome if it returned in force.

2. The true underlying cause of autism is the ubiquitous commensal virus Human Herpesvirus 6 (HHV-6). I was in one of 5 groups which developed this data, but it appears to have vanished from the public and academic eye. Some, but probably not all vaccines and environmental agents act to create ASD by "riling up" HHV-6 which is present lifelong in oligodendrocytes in the brains of everybody, and is thus in a position to do the damage that defines autism. Research on which vaccines "rile up" HHV-6, and which do not, is sorely lacking.

3. The MMR is a highly effective vaccine, but it is also dangerous. It contains three attenuated viruses, measles, mumps and rubella, each of which can infect brain cells and can cause some neurological damage. Measles virus is especially dangerous, because it strongly infects all neural cell types and can possibly cause autism by itself, even without "riling up" HHV-6.

4. Except for the MMR, the fears of the CDC are probably misplaced, since HHV-6 is not a vaccine virus. Therefore, it makes sense to delay the administration of the MMR vaccine until the child reaches the age of 3 , beyond the age at which neurological damage can cause ASD, even at the risk of starting a measles epidemic. This topic deserves serious discussion and clinical trials.

\section{Acknowledgement}

I note that this article was sponsored by the Weston A. Price Foundation; an organization that I believe has the best interests of the American Public at heart. I do not agree with the Foundation's call for Congress to remove oversight of vaccines from the Department of Health and Human Services, however. Some government oversight will always be necessary, and DHHS is a good as any other agency, once they are educated as to the correct facts and approaches as outlined in this article.

\section{References}

1. Schrag A, Gilbert R, Giovannoni G, Robertson MM (2009) Streptococcal infection, Tourette syndrome, and OCD: is there a connection? Neurology 73: 1256-1263.

2. Gilbert R, Kurlan R (2009) PANDAS-Horse or Zebra? Neurology 73: 1252-1253.

3. Swedo SE, Leonard HL, Garvey M, Mittleman B, Allen AJ, et al. (1998) Pediatric autoimmune neuropsychiatric disorders associated with streptococcal infections: clinical description of the first 50 cases. Am J Psychiatry. 155: 264-271.

4. Mell LK, Davis RL, Owens D (2005) Association between streptococcal infection and obsessive-compulsive disorder, Tourette's syndrome and tic disorder. Pediatrics 116: 56-60.

5. Kurlan R (1998) Tourette's syndrome and 'PANDAS': will the relation bear out? Neurology 50: 1530-1534.

6. Offitt P (2008) Autism's false prophets. Columbia University Press, New York.

7. Giedd JN, Rapoport JL, Leonard HL, Richter D, Swedo SE (1996) Case study: acute basal ganglia enlargement and obsessive-compulsive symptoms in an adolescent boy. J Am Acad Child Adolesc Psychiatry 35: 913-915.

8. Cunningham MW (2016) Post-streptococcal autoimmune sequelae: Rheumatic fever and beyond. In: Ferretti JJ, Stevens DL, Fischetti VA, (eds). Streptococcus pyogenes. Basic biology to clinical manifestations. Oklahoma City, University of Oklahoma Health Sciences Center.

9. Blumberg BM, Menonna J, Adamus J, Fortunato J, Kolakofsky D, et al. (1985) The majority of SSPE genomes are complete. J. Neurol 232: 266, XIIIth World Congress of Neurology, Hamburg, Germany 1-6.

10. Farhood Z, Ong AA, Discolo CM (2016) PANDAS: A systematic review of treatment options. Int J Pediatr Otorhinolaryngol 89: 149-153.

11. Helm CE, Blackwood RA (2015) Pediatric autoimmune neuropsychiatric disorder associated with streptococcal infections (PANDAS): Experience at a tertiary referral center. Tremor Other Hyperkinetic Movements 5: $1-5$. 
Citation: Blumberg BM (2016) The Signature: A Never-Sent Letter to the Editors of Neurology, Updated With Commentary and Guidelines for the Future. J Neurol Disord 4: 313. doi:10.4172/2329-6895.1000313

Page 4 of 4

12. Kovacevic M, Grant P, Swedo SE (2015) Use of intravenous immunoglobulin in trhe treatment of twelve youths with pediatric autroimmune neuropsychiatric disorders associated with streptococcal infections. J Child Adolescent Psychopharmacology 25: 65-69.

13. Williams KA, Swedo SE, Farmer CA, Grantz H, Grant PJ, et al. (2016) Randomized, controlled trial of intravenous immunoglobulin for pediatric autoimmune neuropsychiatric disorders associated with streptococcal infections. JAM Acad Child Adolesc Psychiatry 55: 860-867.

14. Wong PH, White KM (2015). Impact of immunoglobulin therapy in pediatric disease: a review of immune mechanisms. Clin Rev Allergy Immunol.

15. Rohde M, Cleary PP (2016) Adhesion and invasion of Streptococcus pyogenes into host cells and clinical relevance of intracellular streptococci. In: Ferretti JJ, Stevens DL, Fischetti VA, (eds). Streptococcus pyogenes. Basic biology to clinical manifestations. Oklahoma City, University of Oklahoma Health Sciences Center.

16. Autism and the CDC whistleblower (2014) CDC whistleblower to extend MMR vaccine fraud. Retrieved from Natural News.com
17. CDC Whistleblower to Extend MMR Vaccine Fraud (2016) First print publication of this material in the Townsend Letter. 399: 26.

18. Mohammad Y, Al-Hussain F, Hussain S, Al Raddadi KK (2016) Traditional treatment of epilepsy; trepanation revisited. Neurology 87: 1064 .

19. The Marshall Protocol (2009) The Marshall plan study site- An overview of the protocol and its derivation.

20. Proal AD, Albert PJ, Marshall TG (2014) Inflammatory disease and the human microbiome. Discovery Medicine 17: 257-265.

21. Zaharodny W, Shenouda J, Howell S, Rosato NS, Peng B, et al. (2014). Increasing autism prevalence in metropolitan New Jersey. Autism 18: 117-126.

22. Healthy People (2000) A bulletin issued by the US Department of Health and Human Services to NIH grantees that explains the new vaccine program and its purposes.

23. Offitt PA (2011) Deadly choices: How the anti-vaccine movement threatens us all. Basic Books, 387 Park Avenue South, New York, NY 10016. 